\title{
Screening for Depression in African-American Churches
}

\author{
Sidney H. Hankerson, MD, MBA, ${ }^{1}$ Young A Lee, BA, ${ }^{2}$ David K. Brawley, MTS, ${ }^{3}$ Kenneth Braswell $^{4}$ \\ Priya J. Wickramaratne, $\mathrm{PhD},{ }^{5}$ Myrna M. Weissman, $\mathrm{PhD}^{1}$
}

\begin{abstract}
Introduction: Substantial racial/ethnic disparities exist in the identification and management of major depression. Faith-Based Health Promotion interventions reduce disparities in health screenings for numerous medical conditions. However, the feasibility of systematically screening for depression in faith-based settings has not been investigated. The purpose of this study was to assess the feasibility of using a validated instrument to screen for depression in African-American churches.
\end{abstract}

Methods: Participants were recruited between October and November 2012 at three predominantly African-American churches in New York City. A participatory research approach was used to determine screening days. The Patient Health Questionnaire-9 (PHQ-9) was administered to 122 participants. Positive depression screen was defined as a PHQ-9 score $\geq 10$. Descriptive statistics were used to report sample characteristics, prevalence of participants who screened positive, and history of help seeking. Logistic regression analyses were conducted to determine the association of positive depression screen and sociodemographic characteristics. Initial analyses were conducted in 2013, with additional analyses in 2014 .

Results: The prevalence estimate for positive depression screen was 19.7\%. More men (22.5\%) screened positive than women (17.7\%). Total household income was inversely related to positive depression screen. A similar percentage of respondents had previously sought help from primary care providers as from clergy.

Conclusions: It was feasible to screen for depression with the PHQ-9 in African-American churches. The prevalence of positive depression screen was high, especially among black men. Churches may be an important setting in which to identify depressive symptoms in this underserved population.

(Am J Prev Med 2015;49(4):526-533) @ 2015 American Journal of Preventive Medicine

\section{Introduction}

S ubstantial racial/ethnic disparities exist in the identification and management of major depressive disorder (MDD) ${ }^{1,2}$ African Americans with MDD, compared with non-Hispanic white Americans, are more

From the ${ }^{1}$ Columbia University College of Physicians and Surgeons, New York State Psychiatric Institute, New York, New York; ${ }^{2}$ Department of Epidemiology, New York State Psychiatric Institute, New York, New York; ${ }^{3}$ St. Paul Community Baptist Church, Brooklyn, New York; ${ }^{4}$ Fathers Incorporated, Dunwoody, Georgia; and ${ }^{5}$ Department of Psychiatry, Columbia University Medical Center, Columbia University, New York, New York

Address correspondence to: Sidney $\mathrm{H}$. Hankerson, MD, MBA, Columbia University College of Physicians and Surgeons, New York State Psychiatric Institute, 1051 Riverside Drive, Unit 24, New York NY 10032.

E-mail: hankerss@nyspi.columbia.edu.

0749-3797/\$36.00

http://dx.doi.org/10.1016/j.amepre.2015.03.039 disabled $^{3}$ and less likely to seek treatment. ${ }^{1,2,4-6}$ African Americans with MDD who do seek treatment are more likely to receive care in emergency departments, ${ }^{7}$ receive low-quality care, ${ }^{8}$ and terminate prematurely. ${ }^{9}$ Underrecognition by clinicians, who are less likely to detect MDD among African Americans in primary care, ${ }^{10-12}$ also contributes to racial treatment disparities. Implementing depression screening programs in trusted community-based settings holds promise for identifying individuals who may be at risk for nondetection in traditional medical settings.

Faith-Based Health Promotion (FBHP) has received growing interest as a way to reduce disparities in depression case finding. ${ }^{13-17}$ FBHP has demonstrated efficacy in screening and improving patient health outcomes for numerous medical conditions, ${ }^{18}$ including cancer, ${ }^{19}$ cardiovascular disease, ${ }^{20}$ and HIV/AIDS. ${ }^{21}$ 
African Americans have the highest rates of church attendance among all racial/ethnic groups in the U.S., ${ }^{22,23}$ which makes churches viable catchment settings for depression screening. ${ }^{24-26}$ African-American clergy provide the primary source of mental health care for a socioeconomically diverse cohort of community members and are trusted "gatekeepers" for referrals to mental health specialists. ${ }^{27}$ However, a recent systematic review of African-American church-based programs for DSM-IV mental disorders yielded just one study in which depression was the primary outcome. ${ }^{28}$ Mynatt et al. $^{29}$ delivered group psychotherapy in an AfricanAmerican church and found significant reductions in depression scores at post-intervention assessment.

The rationale for the current study was established via focus groups with 21 African-American clergy to ascertain their perspectives about screening for depression in black churches. ${ }^{30}$ Clergy insisted that any screening instrument utilized in the church must be anonymous and brief. Clergy emphasized partnering with academic researchers to conduct screenings in small group settings, such as at health fairs, held at the church. Clergy were opposed to screening during Sunday services because they thought it would disrupt the flow of service. ${ }^{30}$

Therefore, the settings for the present study were three black churches in New York City. The primary aim was not to conduct an epidemiologic survey of depression prevalence. Instead, the study's objective was to assess the feasibility of screening for depression with a validated instrument in African-American churches. This report represents the first published study to systematically screen for depression in African-American churches.

\section{Methods}

\section{Study Design and Procedures}

We utilized a participatory research approach ${ }^{31-33}$ to engage church leaders. The primary investigator (PI) contacted key church stakeholders to discuss the study rationale and design. Church stakeholders then facilitated either an in-person meeting or teleconference between the PI and lead pastor of their respective church. During these meetings, the lead pastor of each church reviewed the depression screening instrument and selected the FBHP program during which screenings would be conducted. Pastors agreed to announce the date of the FBHP program during Sunday services. The PI agreed to conduct a mental health educational workshop at each church to set the stage for depression screenings at each FBHP. Finally, each pastor provided a signed letter of support to the IRB authorizing use of their church as a study site.

Key church stakeholders and the PI distributed a description sheet to explain the study procedures to all interested participants. Eligible participants were not required to sign informed consent forms, as determined by the IRB, because the survey was anonymous and no identifying data were collected. No data were collected on community members who declined to participate, so we were unable to calculate the survey's completion rate. Treatment was not provided as part of the study. However, participants who requested referrals to mental health specialists were provided with a list of community mental health resources.

Research personnel collected the completed surveys and put them into a labeled envelope. Participants were instructed to discuss any concerns about survey responses with the PI before leaving the church. Certain safeguards, including a thorough psychiatric assessment and documentation of a Safety Plan, ${ }^{34}$ were planned if participants expressed suicidality or needed urgent care. These safety measures were never used.

\section{Study Sample}

Participants were recruited between October and November 2012 from three predominantly African-American churches (two Baptist and one African Methodist Episcopal) in New York City. The Baptist and Methodist denominations represent the two largest historically black church denominations in the U.S. ${ }^{35}$ Each church is classified as a "mega-church," defined as having at least 2,000 worshippers throughout the course of a weekend. ${ }^{36}$ Inclusion criteria for the study were adults aged 18-70 years and English fluency. Participants were excluded if they had any medical condition (e.g., chest pain) that compromised ability to participate as assessed by self-report or clinician judgment.

Demographic characteristics of ZIP codes where each church is geographically located were assessed via the 2009-2013 Five-Year American Community Survey (U.S. Census Bureau). "Church A" is in a community with $64.1 \%$ African Americans. Participants from Church A were recruited from an FBHP program that occurred on a Saturday morning. The program focused on psychosocial stressors facing African-American men. Women and men were present and eligible to participate. "Church B" is in a community with $71.2 \%$ African Americans. Participants at Church B were recruited from an FBHP program that occurred during a weekday morning. African-American men were the target audience and all program attendees were men. "Church C" is in a community with $83.1 \%$ African Americans. Participants at Church $\mathrm{C}$ were recruited from an FBHP program designed to increase awareness about depression in the African-American community. The program took place on a weeknight and featured a keynote address by the director of a national social service agency and panel discussion by mental health professionals. This study received IRB approval from the New York State Psychiatric Institute (\#6368).

\section{Measures}

Data were collected on participants' gender, age, race/ethnicity, marital status, education level, total household income, current work situation, and current health insurance. The Patient Health Questionnaire-9 (PHQ-9) was used to screen for depressive symptoms in the preceding 2 weeks. ${ }^{37}$ The PHQ-9 is a brief selfreport measure shown to be valid and reliable among African Americans in clinical and population samples. ${ }^{38-40}$ It has been used to screen, diagnose, and monitor treatment response for depression. ${ }^{41-43}$ The nine questions on the PHQ-9 correspond to the nine symptoms of depression as defined by the DSM-IV. ${ }^{44} \mathrm{~A}$ PHQ-9 score $\geq 10$ has been recommended as the single cutoff 
point for a provisional diagnosis of depression, with a sensitivity and specificity of $88 \%{ }^{45}$ A positive depression screen on the PHQ9 must be confirmed with a clinical interview. Depressive scores of 0-4 indicate "no depression," 5-9 are "mild," 10-14 are "moderate," $15-19$ are "moderately severe," and $\geq 20$ are "severe." We defined PHQ-9 $\geq 10$ as "positive depression screen."

History of mental health treatment was assessed with the following multiple-response question: Did you ever go to see any of the professionals listed below because you had an emotional or mental problem? (check all that apply): a) mental health professional (e.g., psychiatrist, psychologist, social worker); b) your primary care or medical doctor; c) a religious or spiritualist advisor like a minister or priest; d) any other healer like an herbalist, chiropractor, or spiritualist; e) other (please fill in). Each treatment category had two response options: yes or no. Participants were instructed to check all applicable responses. The frequency of each category was calculated by dividing the number of respondents in each category by the total number of respondents who answered this question. The complete survey is in the Appendix (available online).

\section{Statistical Analysis}

Racial background had four categories: black, Hispanic, Asian/ Pacific Islander, and other. We created a dichotomous variable (black or non-black) by collapsing the three non-black categories into a single category, collectively labeled as "non-black." Marital status originally had four categories (married, separated/divorced, widowed, and single/never married), and we combined separated/ divorced and widowed into one category for logistic regression analyses. We classified education into four categories $(\leq 12$ th grade, high school graduate, some college or technical school, and completed $\geq 4$ years of college) for descriptive analyses and three categories (some college and completed 4 years of college were collapsed into one category) for regression analyses. We classified household income into four categories $(\$ 0-\$ 19,999 ; \$ 20,000-$ $\$ 34,999 ; \$ 35,000-\$ 69,999$; and $\geq \$ 70,000)$. Current work situation was a multiple-response question divided into the following six categories: worker for pay, homemaker, student, retired, disabled, and unemployed. Health insurance was a multiple-response question with the following six categories: Medicare, Medicaid, other government program, private health insurance, out of pocket/no coverage, and other. We created a dichotomous variable whereby out of pocket/no coverage was coded as "uninsured" and all other categories were labeled as "insured."

Descriptive statistics were used to report sample characteristics and prevalence of positive depression screen by gender. To calculate prevalence estimates, we calculated the total sum score of the nine items on the PHQ-9. We imputed a value of 0 ("not at all") for all missing responses on the PHQ-9. This imputation scheme resulted in a conservative estimate of depression prevalence. The distribution of these scores was then divided into the established intervals of depression severity with the PHQ-9. We created a variable, "positive depression screen," which included respondents whose PHQ-9 score is $\geq 10$. We conducted univariate logistic regression analyses for each demographic variable to determine if any sociodemographic characteristics were associated with a positive screen. Those variables found to be significant at the 0.05 level were included in a multivariate logistic regression to determine their simultaneous association with depression prevalence. We calculated proportion of participants with a history of ever seeking mental health treatment by dividing the number of respondents in each category by the total number of respondents who ever sought treatment. Reference categories are the lowest level of each variable. All analyses were conducted using IBM SPSS Statistics software, version 21.0. Initial analyses were conducted in 2013, with additional analyses in 2014.

\section{Results}

The demographic characteristics of our sample $(\mathrm{N}=122)$ are presented by gender for each church in Table 1 . The mean age of all participants was $53.7(\mathrm{SD}=13.33)$ years, and most were women (55.9\%). In terms of racial selfidentification, 116 participants were black, 2 were Hispanic, 1 was Asian/Pacific Islander, and 2 were "other." At Church A, most participants were men (67.9\%), had some college (69\%), and were separated/widowed/ divorced (69\%). The most frequently observed household income level and employment status were $\$ 45,000$ $\$ 59,999$ (34\%) and worker for pay (46.9\%), respectively. At Church B, men $(n=8)$ comprised the entire sample. A majority of these men were high school graduates $(62.5 \%)$, were separated/widowed/divorced $(75 \%)$, and earned $\$ 0-\$ 19,999$ (50\%). The most frequently observed employment status was disabled (37.5\%). At Church C, the majority of participants were women (70.7\%), high school graduates (51.8\%), and separated/widowed/ divorced (68.2\%). The most frequently observed household income level and employment status were $\$ 30,000-\$ 44,999$ (33.8\%) and worker for pay (39.6\%), respectively.

Table 2 shows that $19.7 \%$ of the total sample had a positive depression screen. A slightly higher percentage of men $(22.5 \%)$ screened positive than women (17.7\%), but these results did not reach statistical significance. More women (3.2\%) had "severe" depression than men $(0 \%)$. Of note, none of the participants expressed concerns about their survey responses to the PI and none requested community mental health referrals.

Age, education, and total household income predicted positive depression screen (Table 3). Those with a total household income of $\$ 35,000-\$ 69,999$ (AOR $=0.17,95 \%$ $\mathrm{CI}=0.04,0.79$ ) were significantly less likely to have screened positive compared with the reference category $(\$ 0-\$ 19,999)$. There was a nonsignificant trend for people with income $>\$ 70,000 \quad(\mathrm{AOR}=0.16,95 \%$ $\mathrm{CI}=0.02,1.02)$ to have reduced odds of positive depression screen compared with those in the lowest income bracket.

Figure 1 shows the distribution of treatment sources among those who ever sought help. Overall, 63.9\% $(n=78)$ of participants had previously sought help for a 
Table 1. Demographic Characteristics of Participants $(n=122)$ at Three African-American Churches

\begin{tabular}{|c|c|c|c|c|c|}
\hline \multirow[b]{2}{*}{ Demographics, \% } & \multicolumn{2}{|c|}{ Church A } & \multirow{2}{*}{$\begin{array}{l}\text { Church } \mathrm{B}^{\mathrm{a}} \\
\text { Men }(n=8)\end{array}$} & \multicolumn{2}{|c|}{ Church C } \\
\hline & Men $(n=19)$ & Women $(n=9)$ & & Men $(n=22)$ & Women $(n=53)$ \\
\hline Gender $^{\mathrm{b}}$ & 67.9 & 32.1 & 100 & 29.3 & 70.7 \\
\hline Age, y, mean (SD) & $48.1(12.9)$ & $55.7(7.0)$ & $52.1(8.5)$ & $53.2(16.5)$ & $56.0(13.5)$ \\
\hline \multicolumn{6}{|l|}{ Race $^{c}$} \\
\hline Black & 94.7 & 88.9 & 87.5 & 90.9 & 100 \\
\hline Non-black & 5.3 & 11.1 & 12.5 & 9.1 & 0.0 \\
\hline \multicolumn{6}{|l|}{ Marital status } \\
\hline Married & 21.1 & 44.4 & 25.0 & 50.0 & 24.5 \\
\hline Separated/divorced/widowed & 78.9 & 55.5 & 75.0 & 50.0 & 75.4 \\
\hline Single/never married & 0.0 & 0.0 & 0.0 & 0.0 & 0.0 \\
\hline \multicolumn{6}{|l|}{ Education level } \\
\hline$\leq 12$ th grade & 0.0 & 0.0 & 12.5 & 13.6 & 5.7 \\
\hline High school graduate & 47.4 & 0.0 & 62.5 & 59.1 & 49.1 \\
\hline Some college $/ \geq 4$ years college & 52.6 & 100 & 25.0 & 27.3 & 45.3 \\
\hline \multicolumn{6}{|l|}{ Total household income ${ }^{d}$} \\
\hline$\$ 0-\$ 19,999$ & 27.8 & 14.3 & 50.0 & 31.8 & 12.5 \\
\hline$\$ 20,000-\$ 34,999$ & 11.1 & 14.3 & 12.5 & 13.6 & 25.0 \\
\hline$\$ 35,000-\$ 69,999$ & 27.8 & 42.9 & 37.5 & 27.3 & 39.6 \\
\hline$\geq \$ 70,000$ & 33.3 & 28.6 & 0.0 & 27.3 & 22.9 \\
\hline \multicolumn{6}{|l|}{ Current work situation ${ }^{e}$} \\
\hline Worker for pay & 47.4 & 55.6 & 12.5 & 33.3 & 43.4 \\
\hline Homemaker & 0.0 & 0.0 & 0.0 & 0.0 & 3.8 \\
\hline Student & 5.3 & 11.1 & 12.5 & 9.5 & 3.8 \\
\hline Retired & 10.5 & 11.1 & 25.0 & 42.9 & 41.5 \\
\hline Disabled & 21.1 & 11.1 & 37.5 & 14.3 & 11.3 \\
\hline Unemployed & 21.1 & 33.3 & 12.5 & 9.5 & 9.4 \\
\hline \multicolumn{6}{|l|}{ Current health insurance ${ }^{f}$} \\
\hline Insured & 100.0 & 100.0 & 87.5 & 90.9 & 100.0 \\
\hline Uninsured & 0.0 & 0.0 & 12.5 & 9.1 & 0.0 \\
\hline
\end{tabular}

${ }^{a}$ Church $\mathrm{B}$ did not have any female respondents.

${ }^{\mathrm{b}}$ Missing $\mathrm{NA}=1(3.4 \%)$, missing $\mathrm{NC}=10(11.8 \%)$.

${ }^{\mathrm{c}}$ Missing $\mathrm{NC}=1$ (1.2\%).

${ }^{\mathrm{d}}$ Missing NA $=3$ (10.3\%), missing $\mathrm{NC}=5$ (5.9\%).

${ }^{\mathrm{e}}$ Missing $\mathrm{NC}=1$ (1.2\%).

${ }^{f}$ Missing $\mathrm{NB}=1$ (11.1\%), missing $\mathrm{NC}=3$ (3.5\%).

mental health problem. Prevalence estimates of past treatment were slightly greater among women (54.9\%) than men (45.1\%), but these results were not statistically significant. Men most frequently sought help from a mental health professional, whereas women most frequently sought help from a primary care or medical doctor. A similar percentage of men (53.1\%) and women (53.8\%) sought help from a minister or priest. 
Table 2. Prevalence of Positive Depression Screen by Gender $(n=111)^{a}$ at Three African-American Churches

\begin{tabular}{|lcc|}
\hline Depression severity, \% & Men $(\boldsymbol{n}=\mathbf{4 9})$ & Women $(\boldsymbol{n}=\mathbf{6 2})$ \\
\hline None (0-4) & 55.1 & 58.1 \\
Minimal (5-9) & 22.4 & 24.2 \\
Moderate (10-14) & 18.4 & 14.5 \\
$\begin{array}{l}\text { Moderately severe } \\
\text { (15-19) }\end{array}$ & 4.1 & 0.0 \\
Severe (20-27) & 0.0 & 3.2 \\
$\begin{array}{l}\text { Positive Depression } \\
\text { Screen ( } \geq 10)\end{array}$ & 22.5 & 17.7 \\
\hline
\end{tabular}

${ }^{\mathrm{a}}$ Gender was not reported for 11 participants.

\section{Discussion}

This study represents the first published study of depression screenings conducted in African-American churches. Importantly, it was feasible to screen for depression by partnering with pastors and key church stakeholders. The sample size and sampling strategy require that findings be interpreted cautiously. The next planned phase of this project is to test the feasibility and acceptability of training African-American clergy an evidence-based depression intervention. We discuss the study's implications and suggest areas for future research.

The prevalence estimate of positive depression screen was high (19.7\%) and similar to rates found in urban primary care settings. ${ }^{46}$ This prevalence estimate was higher than that observed among black Americans in representative community samples. ${ }^{3,47}$ The context in which screenings were conducted may have contributed to these high rates. At Church A and Church C, for

Table 3. Positive Depression Screen by Risk Category

\begin{tabular}{|lcc|}
\hline Risk category & Unadjusted OR (95\% CI) & Adjusted OR (95\% CI) \\
\hline Age & $0.95(0.92,0.98)$ & $0.96(0.92,1.00)$ \\
Education level & 1 (ref) & 1 (ref) \\
$\leq 12$ th grade & $0.24(0.05,1.20)$ & $0.42(0.05,3.66)$ \\
High school graduate & $\mathbf{0 . 0 9}(0.02,0.49)$ & $0.28(0.26,2.93)$ \\
Some college/ $\geq 4$ years college & $1($ ref $)$ & $1($ ref $)$ \\
Total household income & $0.35(0.10,1.25)$ & $0.62(0.15,2.52)$ \\
$\$ 0-\$ 19,999$ & $\mathbf{0 . 1 0}(0.02,0.42)$ & $\mathbf{0 . 1 7}(0.04,0.79)$ \\
$\$ 20,000-\$ 34,999$ & $\mathbf{0 . 0 8}(0.16,0.44)$ & $0.16(0.02,1.02)$ \\
$\$ 35,000-\$ 69,999$ & & \\
$\$ 70,000$ or more & & \\
\hline
\end{tabular}

Note: Boldface indicates statistical significance $(p<0.05)$. example, depression screenings were conducted at FBHP programs specifically focused on raising awareness about mental health in the African-American community. Participants facing psychological distress may have been attracted to these particular programs to obtain mental health resources. Future church-based depression screenings could be conducted in FBHP programs that do not specifically focus on mental health and in other small group meetings held at the church.

An important finding was the high percentage of black men who screened positive for depression. Although not statistically significant, we found that $22.5 \%$ of men and $17.7 \%$ of women screened positive. It is well known that women have higher prevalence estimates of depression compared with men, and this gender difference is consistent across diverse cultures. ${ }^{48}$ The timing of screening days may have contributed to observed gender difference among those who screened positive. At Church B, men comprised the entire sample and were recruited during a weekday morning. More men recruited from this church had low household incomes, were disabled, and had public health insurance compared with men at the other two churches in our study. The low SES of these men may have increased their risk of having a positive screen. Alternatively, men at Church B may have attended the daytime FBHP program to enhance their social connectedness, as black churches are renowned for providing social support to community members. ${ }^{49-52}$

The high rates of depressed men in our sample may have etiologic and treatment implications. Kendler and Gardner ${ }^{53}$ recently found that men were more likely to become depressed in the context of financial, occupational, and legal stressful events, whereas women's depression was attributed to deficiencies in interpersonal relationships. ${ }^{48,53}$ These gender findings appear to be especially pertinent for black men, who have the highest unemployment rates in the U.S. ${ }^{54}$ and are disproportionately represented in the criminal justice system. ${ }^{55}$ The men who screened positive in our sample had lower SES relative to the depressed women. Given these possible gender differences in depressogenic risk factors, black men may perceive traditional mental health services to be ill equipped to meet their needs. ${ }^{56}$ Our ability to 


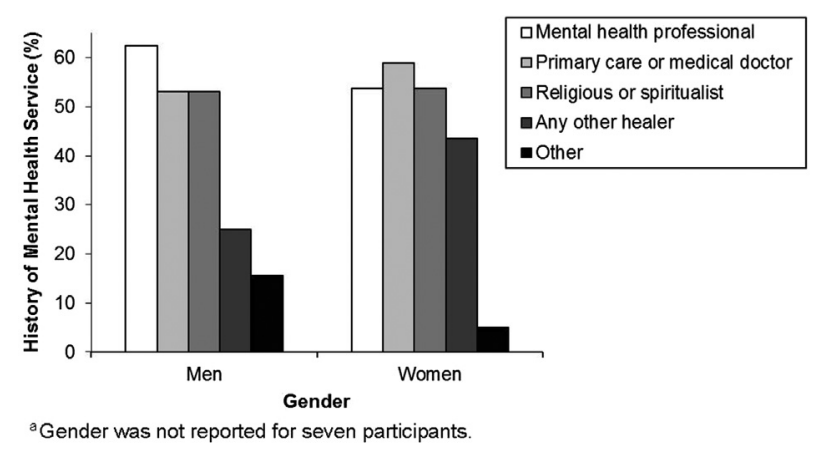

Figure 1. Sources of Care Among Participants $(n=78)$ With a History of Seeking Mental Health Treatment.

screen and identify a high percentage of depressed men suggests that churches are important entry points for engaging black men in mental health care. ${ }^{57,58}$

A majority of the sample had previously sought help for a mental health problem. This finding was surprising, given well-documented treatment disparities. ${ }^{1,4,5}$ For the most part, participants sought treatment equitably from primary care physicians, mental health professionals, and clergy. Primary care settings currently provide the majority of mental health treatment in the U.S. ${ }^{59,60}$ However, African Americans in primary care are more likely to have unmet mental health needs compared with non-Hispanic white Americans. ${ }^{11}$ Multifaceted primary care depression interventions $^{61,62}$ and those utilizing principles of communitypartnered research appear especially promising to reduce disparities. $^{63,64}$ This suggests that investigators should cultivate interdisciplinary relationships across clinical and community settings. Future studies should examine how clinical and community partnerships impact treatment seeking and retention among depressed black adults.

\section{Limitations}

We must acknowledge the study's limitations. Our small aggregate sample size $(\mathrm{N}=122)$ and churches' location in New York City limit generalizability to other settings. All participants were recruited from FBHP programs held at respective churches. However, this sampling strategy was informed by our qualitative data, collaboratively agreed upon by church stakeholders and academicians, and is consistent with other recruitment strategies utilized in churches. ${ }^{65}$ Owing to the cross-sectional design, we cannot make causal interpretations. Finally, we did not collect data on current mental health treatment (i.e., during the prior 30 days) or the quality of care received, so we cannot comment on participants' current treatment needs or their satisfaction with care. Future research is needed to assess the feasibility of screening for depression in churches that vary in congregational size, demographic characteristics, geographic location, and ethnicity. As none of the participants requested referrals to mental health services, we suggest that longitudinal studies be conducted to identify how community-based screenings may lead to increased utilization of mental health services.

Despite these limitations, our study has several strengths. We utilized a validated, widely used screening instrument (PHQ-9). We conducted screenings in three separate churches that represent the two largest AfricanAmerican denominations in the U.S. (Baptist and Methodist). We recruited a significant percentage of black men, who have traditionally been under-represented in clinical research. ${ }^{66}$ By partnering with key church stakeholders and pastors, we extended strategies for community engagement in faith-based settings. ${ }^{18}$

\section{Conclusions}

It was feasible to screen for depression with the PHQ-9 in three African-American churches. Black men were more likely to screen positive compared with black women, which may have been linked to lower SES among the men in our sample. This study advances the scant literature on FBHP for depression. Our findings lay the groundwork for expanding access to depression case finding and treatment referral in African-American churches.

Dr. Hankerson was supported by grants 1 K23 MH10254001A1 and 5-T32 MH015144 from the National Institute of Mental Health (NIMH) and grant 17694 from the Brain \& Behavior Foundation (formerly the National Alliance for Research on Schizophrenia and Depression [NARSAD]). Dr. Weissman was supported by NIMH, NARSAD, the Sackler Foundation, and the Templeton Foundation, and receives royalties from the Oxford University Press, Perseus Press, the American Psychiatric Association Press, and MultiHealth Systems. Dr. Wickramaratne was supported by NIMH and the Templeton Foundation. We would like to thank the clergy, ministry leaders, and other community members for their unwavering support and commitment to completing this study.

No other financial disclosures were reported by the authors of this paper.

\section{References}

1. Hankerson SH, Fenton MC, Geier TJ, Keyes KM, Weissman MM, Hasin DS. Racial differences in symptoms, comorbidity, and treatment for major depressive disorder among black and white adults. J Natl Med Assoc. 2011;103(7):576-584.

2. Gonzalez HM, Vega WA, Williams DR, Tarraf W, West BT, Neighbors HW. Depression care in the United States: too little for too few. Arch Gen Psychiatry. 2010;67(1):37-46. http://dx.doi.org/10.1001/arch genpsychiatry.2009.168.

3. Williams DR, Gonzalez HM, Neighbors H, et al. Prevalence and distribution of major depressive disorder in African Americans, Caribbean blacks, and non-Hispanic whites: results from the National 
Survey of American Life. Arch Gen Psychiatry. 2007;64(3):305-315. http://dx.doi.org/10.1001/archpsyc.64.3.305.

4. Alegria M, Chatterji P, Wells K, et al. Disparity in depression treatment among racial and ethnic minority populations in the United States. Psychiatr Serv. 2008;59(11):1264-1272. http://dx.doi.org/10.1176/ ps.2008.59.11.1264.

5. Gonzalez HM, Croghan T, West B, et al. Antidepressant use in black and white populations in the United States. Psychiatr Serv. 2008;59 (10):1131-1138. http://dx.doi.org/10.1176/ps.2008.59.10.1131.

6. Harman JS, Edlund MJ, Fortney JC. Disparities in the adequacy of depression treatment in the United States. Psychiatr Serv. 2004;55 (12):1379-1385. http://dx.doi.org/10.1176/appi.ps.55.12.1379.

7. Snowden LR, Catalano R, Shumway M. Disproportionate use of psychiatric emergency services by African Americans. Psychiatr Serv. 2009;60(12):1664-1671. http://dx.doi.org/10.1176/ps.2009.60.12.1664.

8. Schraufnagel TJ, Wagner AW, Miranda J, Roy-Byrne PP. Treating minority patients with depression and anxiety: what does the evidence tell us? Gen Hosp Psychiatry. 2006;28(1):27-36. http://dx.doi.org/ 10.1016/j.genhosppsych.2005.07.002.

9. Ayalon L, Alvidrez J. The experience of black consumers in the mental health system-identifying barriers to and facilitators of mental health treatment using the consumers' perspective. Issues Mental Health Nurs. 2007;28(12):1323-1340. http://dx.doi.org/10.1080/01612840701651454.

10. Carrington $\mathrm{CH}$. Clinical depression in African American women: diagnoses, treatment, and research. J Clin Psychol. 2006;62(7):779-791. http://dx.doi.org/10.1002/jclp.20289.

11. Borowsky SJ, Rubenstein LV, Meredith LS, Camp P, Jackson-Triche M, Wells KB. Who is at risk of nondetection of mental health problems in primary care? J Gen Intern Med. 2000;15(6):381-388. http://dx.doi.org/ 10.1046/j.1525-1497.2000.12088.x.

12. Gallo JJ, Bogner HR, Morales KH, Ford DE. Patient ethnicity and the identification and active management of depression in late life. Arch Intern Med. 2005;165(17):1962-1968. http://dx.doi.org/10.1001/ archinte.165.17.1962.

13. Stansbury KL, Brown-Hughes T, Harley DA. Rural African American clergy: are they literate on late-life depression? Aging Ment Health. 2009;13(1):9-16. http://dx.doi.org/10.1080/13607860802154424.

14. Kramer TL, Blevins D, Miller TL, Phillips MM, Davis V, Burris B. Ministers' perceptions of depression: a model to understand and improve care. J Relig Health. 2007;46(1):123-139. http://dx.doi.org/ 10.1007/s10943-006-9090-1.

15. Blank MB, Mahmood M, Fox JC, Guterbock T. Alternative mental health services: the role of the black church in the South. Am J Public Health. 2002;92(10):1668-1672. http://dx.doi.org/10.2105/AJPH.92.10.1668.

16. Bryant K, Haynes T, Kim Yeary KH, Greer-Williams N, Hartwig M. A rural African American faith community's solutions to depression disparities. Public Health Nurs. 2014;31(3):262-271. http://dx.doi.org/ 10.1111/phn.12079.

17. Bryant K, Haynes T, Greer-Williams N, Hartwig MS. “Too blessed to be stressed": a rural faith community's views of African-American males and depression. J Relig Health. 2014;53(3):796-808. http://dx.doi.org/ 10.1007/s10943-012-9672-z.

18. DeHaven MJ, Hunter IB, Wilder L, Walton JW, Berry J. Health programs in faith-based organizations: are they effective? Am J Public Health. 2004;94(6):1030-1036. http://dx.doi.org/10.2105/AJPH.94.6.1030.

19. Bowie JV, Wells AM, Juon H-S, Sydnor KD, Rodriguez EM. How old are African American women when they receive their first mammogram? Results from a church-based study. J Community Health. 2008;33(4):183-191. http://dx.doi.org/10.1007/s10900-008-9092-x.

20. Frank D, Grubbs L. A faith-based screening/education program for diabetes, CVD, and stroke in rural African Americans. Abnf J. 2008;19(3):96-101.

21. Tyrell CO, Klein SJ, Gieryic SM, Devore BS, Cooper JG, Tesoriero JM. Early results of a statewide initiative to involve faith communities in HIV prevention. J Public Health Manag Pract. 2008;14(5):429-436. http://dx.doi.org/10.1097/01.PHH.0000333876.70819.14.
22. Chatters LM, Taylor RJ, Bullard KM, Jackson JS. Race and ethnic differences in religious involvement: African Americans, Caribbean Blacks and non-Hispanic Whites. Ethn Racial Stud. 2009;32(7):11431163. http://dx.doi.org/10.1080/01419870802334531.

23. Wells JN, Cagle CS, Bradley PJ. Building on Mexican-American cultural values. Nursing. 2006;36(7):20-21. http://dx.doi.org/ 10.1097/00152193-200607000-00017.

24. Odulana AA, Kim MM, Isler MR, et al. Examining characteristics of congregation members willing to attend health promotion in African American churches. Health Promot Pract. 2014;15(1):125-133 http://dx.doi.org/10.1177/1524839913480799.

25. De Marco M, Weiner B, Meade SA, et al. Assessing the readiness of black churches to engage in health disparities research. J Natl Med Assoc. 2011;103(9-10):960-967.

26. Austin S, Harris G. Addressing health disparities: the role of an African American health ministry committee. Soc Work Public Health. 2011;26 (1):123-135. http://dx.doi.org/10.1080/10911350902987078.

27. Molock SD, Matlin S, Barksdale C, Puri R, Lyles J. Developing suicide prevention programs for African American youth in African American churches. Suicide Life Threat Behav. 2008;38(3):323-333. http://dx.doi. org/10.1521/suli.2008.38.3.323.

28. Hankerson SH, Weissman MM. Church-based health programs for mental disorders among African Americans: a review. Psychiatr Serv. 2012;63(3):243-249. http://dx.doi.org/10.1176/appi.ps.201100216.

29. Mynatt S, Wicks M, Bolden L. Pilot study of INSIGHT therapy in African American women. Arch Psychiatr Nurs. 2008;22(6):364-374. http://dx.doi.org/10.1016/j.apnu.2007.10.007.

30. Hankerson SH, Watson KT, Lukachko A, Fullilove MT, Weissman M. Ministers' perceptions of church-based programs to provide depression care for african americans. J Urban Health. 2013;90(4):685-698. http://dx.doi.org/10.1007/s11524-013-9794-y.

31. Wong EC, Chung B, Stover G, et al. Addressing unmet mental health and substance abuse needs: a partnered planning effort between grassroots community agencies, faith-based organizations, service providers, and academic institutions. Ethn Dis. 2011;21(3 Suppl 1):S1-107-113.

32. Community Based Participatory Research for Health. In: Minkler M, Wallerstein N, eds. San Francisco: Jossey-Bass Publishing, 2008.

33. Jones L, Wells K, Norris K, Meade B, Koegel P. The vision, valley, and victory of community engagement. Ethn Dis. 2009;19(4 Suppl 6): S63-S6-7.

34. Stanley B, Brown GK. Safety planning intervention: a brief intervention to mitigate suicide risk. Cogn Behav Pract. 2012;19(2):256-264. http://dx. doi.org/10.1016/j.cbpra.2011.01.001.

35. Lincoln CE, Mamiya LH. The Black Church in the African American Experience. Durham, NC and London: Duke University Press, http://dx. doi.org/10.1215/9780822381648.

36. Bopp M, Webb B. Health promotion in megachurches: an untapped resource with megareach? Health Promot Pract. 2012;13(5):679-686. http://dx.doi.org/10.1177/1524839911433466.

37. Spitzer RL, Kroenke K, Williams JB. Validation and utility of a selfreport version of PRIME-MD: the PHQ primary care study. Primary Care Evaluation of Mental Disorders. Patient Health Questionnaire. JAMA. 1999;282(18):1737-1744. http://dx.doi.org/10.1001/jama.282. 18.1737.

38. Reese A, Thorpe R, Bell C, Bowie J, LaVeist T. The effect of religious service attendance on race differences in depression: findings from the EHDICSWB Study. J Urban Health. 2012;89(3):510-518. http://dx.doi.org/ 10.1007/s11524-011-9659-1.

39. Monahan PO, Shacham E, Reece M, et al. Validity/reliability of PHQ-9 and PHQ-2 depression scales among adults living with HIV/AIDS in western Kenya. J Gen Intern Med. 2009;24(2):189-197. http://dx.doi. org/10.1007/s11606-008-0846-z.

40. Chen S, Chiu H, Xu B, et al. Reliability and validity of the PHQ-9 for screening late-life depression in Chinese primary care. Int J Geriatr Psychiatry. 2010;25(11):1127-1133. http://dx.doi.org/10.1002/gps.2442. 
41. Gilbody S, Richards D, Brealey S, Hewitt C. Screening for depression in medical settings with the Patient Health Questionnaire (PHQ): a diagnostic meta-analysis. J Gen Intern Med. 2007;22(11):1596-1602. http://dx.doi.org/10.1007/s11606-007-0333-y.

42. McMillan D, Gilbody S, Richards D. Defining successful treatment outcome in depression using the PHQ-9: a comparison of methods. J Affect Disord. 2010;127(1-3):122-129. http://dx.doi.org/10.1016/ j.jad.2010.04.030

43. Manea L, Gilbody S, McMillan D. Optimal cut-off score for diagnosing depression with the Patient Health Questionnaire (PHQ-9): a metaanalysis. CMAJ. 2012;184(3):E191-E196. http://dx.doi.org/10.1503/ cmaj.110829.

44. American Psychiatric Association. Diagnostic and Statistical Manual of Mental Disorders. 4th ed., Washington, DC: American Psychiatric Association, 1994.

45. Kroenke K, Spitzer RL. The PHQ-9: a new depression diagnostic and severity measure. Psychiatric Ann. 2002;32(9):1-7. http://dx.doi.org/ 10.3928/0048-5713-20020901-06.

46. Olfson M, Shea S, Feder A, et al. Prevalence of anxiety, depression, and substance use disorders in an urban general medicine practice. Arch Fam Med. 2000;9(9):876-883. http://dx.doi.org/10.1001/archfami.9.9.876.

47. Hasin DS, Goodwin RD, Stinson FS, Grant BF. Epidemiology of major depressive disorder: results from the National Epidemiologic Survey on Alcoholism and Related Conditions. Arch Gen Psychiatry. 2005;62 (10):1097-1106. http://dx.doi.org/10.1001/archpsyc.62.10.1097.

48. Weissman MM. Treatment of depression: men and women are different? Am J Psychiatry. 2014;171(4):384-387. http://dx.doi.org/10.1176/ appi.ajp.2013.13121668.

49. Chatters LM, Taylor RJ, Lincoln KD, Nguyen A, Joe S. Church-based social support and suicidality among African Americans and Black Caribbeans. Arch Suicide Res. 2011;15(4):337-353. http://dx.doi.org/ 10.1080/13811118.2011.615703.

50. Mattis JS, Mitchell N, Zapata A, et al. Uses of ministerial support by African Americans: a focus group study. Am J Orthopsychiatry. 2007;77 (2):249-258. http://dx.doi.org/10.1037/0002-9432.77.2.249.

51. Taylor RJ, Lincoln KD, Chatters LM. Supportive relationships with church members among African Americans. Fam Relat. 2005;54 (4):501-511. http://dx.doi.org/10.1111/j.1741-3729.2005.00336.x.

52. van Olphen J, Schulz A, Israel B, et al. Religious involvement, social support, and health among African-American women on the east side of Detroit. J Gen Intern Med. 2003;18(7):549-557. http://dx.doi.org/ 10.1046/j.1525-1497.2003.21031.x.

53. Kendler KS, Gardner CO. Sex differences in the pathways to major depression: a study of opposite-sex twin pairs. Am J Psychiatry. 2014;171 (4):426-435. http://dx.doi.org/10.1176/appi.ajp.2013.13101375.

54. Holden KB, McGregor BS, Blanks SH, Mahaffey C. Psychosocial, socio-cultural, and environmental influences on mental health helpseeking among African-American men. J Mens Health. 2012;9(2):6369. http://dx.doi.org/10.1016/j.jomh.2012.03.002.

55. Dumont DM, Allen SA, Brockmann BW, Alexander NE, Rich JD. Incarceration, community health, and racial disparities. J Health Care
Poor Underserved. 2013;24(1):78-88. http://dx.doi.org/10.1353/hpu. 2013.0000 .

56. Suite DH, La Bril R, Primm A, Harrison-Ross P. Beyond misdiagnosis, misunderstanding and mistrust: relevance of the historical perspective in the medical and mental health treatment of people of color. J Nat Med Assoc. 2007;99(8):879-885.

57. Victor RG, Ravenell JE, Freeman A, et al. Effectiveness of a barber-based intervention for improving hypertension control in black men: the BARBER-1 study: a cluster randomized trial. Arch Intern Med. 2011;171 (4):342-350. http://dx.doi.org/10.1001/archinternmed.2010.390.

58. Hess PL, Reingold JS, Jones J, et al. Barbershops as hypertension detection, referral, and follow-up centers for black men. Hypertension. 2007;49(5):1040-1046. http://dx.doi.org/10.1161/HYPERTENSIONA HA.106.080432.

59. Young AS, Klap R, Sherbourne CD, Wells KB. The quality of care for depressive and anxiety disorders in the United States. Arch Gen Psychiatry. 2001;58(1):55-61. http://dx.doi.org/10.1001/archpsyc.58.1.55.

60. Cooper LA, Gonzales JJ, Gallo JJ, et al. The acceptability of treatment for depression among African-American, Hispanic, and white primary care patients. Med Care. 2003;41(4):479-489. http://dx.doi.org/ 10.1097/01.MLR.0000053228.58042.E4.

61. Katon W, Von Korff M, Lin E, et al. Collaborative management to achieve treatment guidelines. Impact on depression in primary care. JAMA. 1995;273(13):1026-1031. http://dx.doi.org/10.1001/jama. 1995.03520370068039 .

62. Bower P, Gilbody S, Richards D, Fletcher J, Sutton A. Collaborative care for depression in primary care. Making sense of a complex intervention: systematic review and meta-regression. Br J Psychiatry. 2006;189:484-493. http://dx.doi.org/10.1192/bjp.bp.106.023655.

63. Wells KB, Jones L, Chung B, et al. Community-partnered clusterrandomized comparative effectiveness trial of community engagement and planning or resources for services to address depression disparities. J Gen Intern Med. 2013;28(10):1268-1278. http://dx.doi.org/ 10.1007/s11606-013-2484-3.

64. Miranda J, Ong MK, Jones L, et al. Community-partnered evaluation of depression services for clients of community-based agencies in under-resourced communities in Los Angeles. J Gen Intern Med. 2013;28(10):1279-1287. http://dx.doi.org/10.1007/s11606-013-2480-7.

65. Evans KR, Hudson SV. Engaging the community to improve nutrition and physical activity among houses of worship. Prev Chronic Dis. 2014;11:E38. http://dx.doi.org/10.5888/pcd11.130270.

66. Ravenell JE, Whitaker EE, Johnson WE Jr. According to him: barriers to healthcare among African-American men. I Natl Med Assoc. 2008;100(10):1153-1160.

\section{Appendix}

\section{Supplementary data}

Supplementary data associated with this article can be found at, http://dx.doi.org/10.1016/j.amepre.2015.03.039. 